\title{
The Effect of Interdependences of Referral Behaviors on the Quality of Ambulatory Care: Evidence from Taiwan
}

\author{
Wen-Yi Chen (iD \\ Department of Senior Citizen Service \\ Management, National Taichung \\ University of Science and Technology, \\ Taichung City, Taiwan
}

Purpose: The purpose of this study is to investigate the effect of interdependences of healthcare providers' referral behaviors on the quality of ambulatory care. The significance of this study is to address the concern regarding the low quality of ambulatory care due to the lack of a compulsory referral system under Taiwan's National Health Insurance system.

Methods: We applied the dynamic connectedness network analysis to estimate the total connectedness index of the referral behavior network, which was separated into the horizontal and vertical referral behavior components in order to measure the interdependences of horizontal and vertical referral behaviors across hospitals and local clinics, respectively.

Results: Our results suggest that the interdependences of referral behaviors increase the quality of ambulatory care. The harmful effect on the quality of ambulatory care from the interdependences of horizontal referral behaviors within the local clinics sector is more significant than that from the interdependences of horizontal referral behaviors within the hospital sector, and the negative effect on the overall and chronic composite measures of avoidable hospital admissions from the interdependences of vertical behaviors associated with local clinics is more substantial than that from the interdependences of vertical behaviors within the hospital sector.

Conclusion: These results not only highlight the significance of care collaboration between local clinics and hospitals to restrain avoidable hospital admissions of chronic diseases for a better overall quality of ambulatory care, but they also suggest that the surveillance system established for the quality of ambulatory care under the global budget payment scheme for the local clinics sector should target ambulatory care for patients with acute conditions.

Keywords: connectedness network analysis, connectedness index, referral behavior, referral policy, National Health Insurance

\section{Introduction}

\section{Background}

Taiwan's National Health Insurance (NHI) system is a single-payer compulsory social insurance program providing a comprehensive healthcare package with moderate cost-sharing for all residents in Taiwan. This system divides healthcare providers into four levels: local clinics (responsible for primary care), district hospitals (delivering secondary care), regional hospitals (providing tertiary care), and medical centers (dealing with the most complicated illnesses and supporting teaching and research in clinical practices). Almost all healthcare providers are contracted with the National Health Insurance Administration (NHIA), and
Correspondence: Wen-Yi Chen Department of Senior Citizen Service Management, National Taichung University of Science and Technology, 193 Sec I, San-Min Road, Taichung City, 40343, Taiwan

Tel +886422196932

Fax +886422196811

Email chenwen@nutc.edu.tw 
healthcare services are reimbursed through the global budget payment scheme on a fee-for-service basis. Therefore, healthcare providers have strong incentives to compete with the quantity rather than quality of healthcare services in order to gain the targeted profit under a fixed total budget for healthcare services. ${ }^{1}$

It is important to address that hospitals provide extensive ambulatory care services for the general public in Taiwan. Approximately $66-70 \%$ of total healthcare expenditure was spent on ambulatory care services, and hospital ambulatory departments contributed around 55-60\% of these ambulatory care expenditures since Taiwan's NHI system was inaugurated in $1995 .^{2}$ In addition, the healthcare expenditure per visit to ambulatory departments in hospitals was around 2-5 times higher than that to local clinics during the period of $1995-2019 .^{2,3}$ Due to there being no compulsory referral policy imposed on Taiwan's NHI system, the beneficiaries of the NHI program are allowed to visit any number of physicians across different hospitals and clinics without any referral restrictions in Taiwan. Doctor or hospital shopping behaviors are frequently observed among Taiwanese patients seeking ambulatory care from different levels of healthcare providers, and these behaviors have imposed a detrimental effect on both cost and quality of healthcare under Taiwan's NHI system. ${ }^{1,4}$

In order to build a referral system in a way that would effectively constrain ambulatory care spending in the hospital sector, Taiwan's Ministry of Health and Welfare (MOHW) has adopted both demand-side and supply-side policies in an effort to promote two-way referral across different levels of healthcare providers. ${ }^{5}$ The demand-side policy consists of a copayment-differentiating scheme that reduces copayments for referrals to medical centers and regional hospitals but increases copayments for healthcare at a medical center without a referral, and this policy is intended to lead patients to seek healthcare first at local clinics. $^{6}$ The supply-side policy, however, is associated with the use of two-way referrals across different healthcare providers initiated by the so-called NHI Family Doctor Plan, aiming to encourage local clinics and different levels of hospitals in the same residential area to work together as a community healthcare group. ${ }^{6}$ In order to consolidate healthcare providers into a community healthcare group, two-way referrals across different levels of healthcare providers are further promoted through a reimbursement-differentiating mechanism for the interorganizational care collaboration. ${ }^{5}$ In general, hospitals who devote themselves to the treatment of severe illnesses or refer patients who need primary care to local clinics obtain a higher reimbursement payment. Local clinics and hospitals are also encouraged to refer their patients to an appropriate specialist in hospitals or local clinics in the same way, when specialty care is necessary for their patients. ${ }^{5}$

Since the global budget payment scheme began being used to reimburse healthcare services from the hospital sector in 2002, the number of hospitals in Taiwan decreased by $21 \%$ during the period of 2002-2019 due to a severe quantity competition of healthcare services for the share of a fixed total budget for healthcare services. ${ }^{7}$ In addition, since physicians practicing in hospitals are mainly employees of hospitals, the closure of hospitals has led physicians to increasingly practice in local clinics. We found that the number of local clinics in Taiwan increased by $28 \%$ during the same period. ${ }^{7}$ Since the healthcare services provided by local clinics are also reimbursed by the global budget scheme, ${ }^{6}$ both hospitals and local clinics have strong incentives to follow the two-way referral policy in order to look for other financial resources beyond the fixed total budget for healthcare services. Therefore, two-way referral behaviors have become one of the competitive strategies to establish patient-sharing networks, allowing healthcare providers to compete for their own share of a fixed total budget through maintaining loyal patients within the same level of healthcare providers or collaborating with different levels of healthcare providers in order to obtain new patients from referrals.

The effectiveness of demand-side policy on the establishment of a referral system under Taiwan's NHI system has been extensively examined by recent studies, ${ }^{8,9}$ and the quality of ambulatory care under Taiwan's NHI system has been criticized in terms of providing short visit time lengths and failing to provide easy-to-understand explanations to patients. ${ }^{1,4}$ Therefore, in this study, we intend to investigate the effect of interdependences of healthcare providers' referral behaviors (associated with the supplyside policy on the establishment of a referral system) on the quality of ambulatory care from the market competition perspective. Previous studies on the effect of market competition on the quality of healthcare have generated ambiguous results. For example, Jiang et al conducted a systematic review and meta-analysis to investigate the relationship between hospital competition and the quality of inpatient care. ${ }^{10}$ The results generated from their random effect meta-analysis indicated a weak or an 
insignificant association between hospital competition and quality of inpatient care. In addition, Shen et al also performed a comprehensive literature review and metaanalyses on the relationship between hospital competition and 30-day mortality of acute myocardial infarction, and results of their meta-regression analyses also suggested that there is insufficient evidence to support a connection between hospital competition and quality of inpatient care. ${ }^{11}$ Similar to these two meta-analysis studies focusing on the linkage between hospital competition and quality of inpatient care, recent empirical studies found the effect of market competition on quality of healthcare in various healthcare markets to be positive in the homecare market, ${ }^{12}$ negative in the physiotherapy and nursing home markets, ${ }^{13,14}$ and inconsistent in the primary care market. $^{15,16}$

It is important to address that the aforementioned studies exploring the impact of market competition on the quality of healthcare applied to a single competition indicator (such as the Herfindahl-Hirschman index) to measure market competition. Nevertheless, the major shortcoming of using a single competition indicator for measuring market competition is that this ignores the fact that interdependences of healthcare providers' behaviors are the underlying mechanism of market competition. It follows that most of the previous studies investigating the connection between a single competition indicator and the quality of healthcare failed to model the interdependences of healthcare providers' behaviors (constituting a central role in market competition) and regarded the underlying mechanism of market competition processing the quality of healthcare as a black box. ${ }^{10-16}$

In order to establish the linkage between the underlying mechanism of market competition and quality of healthcare, three research questions of this study were proposed as follows: First, whether or not the relationship between the underlying mechanism of market competition and quality of healthcare could be established. Second, how do we model competition and collaboration between hospitals and local clinics and evaluate their impact on the quality of ambulatory care? Third, do the interdependences of healthcare providers' referral behaviors have significant impacts on the quality of healthcare? It follows that the purpose of this study is threefold: First, we unravel the underlying mechanism of market competition black box by estimating Total Connectedness Index (TCI) of the referral behavior network through the dynamic connectedness network analyses, ${ }^{17}$ with the interdependences of referral behaviors across hospitals and local clinics measured by the TCI of the referral behavior network. Second, since competition and collaboration between hospitals and local clinics are well documented in the literature of healthcare service research, ${ }^{18-21}$ the TCI of the referral behavior network was further decomposed into the horizontal and vertical referral behavior components, measuring the interdependences of horizontal and vertical referral behaviors across hospitals and local clinics, respectively. It is essential to note that the former component portrays the coexistence of quantity competition and quality collaboration behaviors within the same level of healthcare providers under a fixed total budget for healthcare services, and the latter component describes the collaboration behaviors across different levels of healthcare providers. Third, the relationship between the interdependences of healthcare providers' referral behaviors and quality of ambulatory care is identified to provide a complete picture of the effect of market competition on quality of ambulatory care.

\section{Literature Review}

The methodology of network analyses is growing in importance in the field of healthcare service research due to its capacity to analyze relational phenomena such as collaboration and coordination between healthcare entities and their inter-reliant activities. ${ }^{22,23}$ The applications of network analysis for healthcare service research include the analyses of the patient referral pathway, ${ }^{24,25}$ the spread of infectious diseases, ${ }^{26,27}$ the dissemination of health technology, new drugs and health intervention programs, ${ }^{28-30}$ the formation of collaborative networks of health professionals, ${ }^{31,32}$ the impact of care coordination and patient-sharing networks on cost and quality of care, ${ }^{33-41}$ and others.

Despite network analysis having abundant applications in healthcare service research, studies incorporating network analyses to reveal the underlying mechanism of healthcare market competition is limited in the literature. To the author's best knowledge, Mascia and Di Vincenzo would be the first published research disentangling the network of interconnected inter-organizational relationships constituting the underlying mechanism of the market competition black box and revealing the effects of both collaborative network ties and competitive linkage of healthcare providers on hospital performance. ${ }^{42}$ The implications generated from their study are twofold: First, collaborative and competitive relationships coexist among hospitals, a scenario termed as "co-opetition". 
Second, hospital productivity is negatively (positively) associated with market competition (care collaboration) among providers. Hence, the evidence supports the existence of trade-offs between collaborative and competitive behaviors with regard to hospital productivity. Following this line of research, Mascia et al conducted a series of research studies utilizing the same data from Mascia and Di Vincenzo ${ }^{42}$ to formally test the relationship between inter-hospital collaboration and competition, and their results suggest that market competition among healthcare providers does not hinder interhospital collaboration but the inter-hospital collaboration is a significant predictor of competitive interdependences among hospitals. ${ }^{43,44}$

Several challenges inherent in the work of Mascia et al are worth to be addressed. First, their results are restricted to patent-sharing data (eg, number of patients shared within the hospital sector) with some specific criteria of threshold (eg, distance) of shared patients that are used to serve as a marker of actual competition and collaboration among the same levels of healthcare providers. Thus, their results are likely to be sensitive to different shared patient threshold criteria of threshold. ${ }^{45}$ Second, the unit of analysis in the aforementioned studies is the number of patients shared among hospitals without any referral path information. Therefore, the unit of analysis in these studies is not a direct measure for healthcare providers' referral behaviors, and, therefore, their analysis is incapable of modeling healthcare providers' referral behaviors.

In response to the challenges of arbitrarily defining a network of healthcare providers without any referral path information, we first included 16 referral behaviors from four levels of healthcare providers (ie, local clinics, district hospitals, regional hospitals, and medical centers) delivering ambulatory care services under Taiwan's NHI system as the entities of the referral behavior network, and aggregate ambulatory referral visits across these four levels of healthcare providers were obtained to acquire the referral path information. Second, the dynamic connectedness network analyses ${ }^{17}$ were used to establish a dynamic connectedness network relationship among various referral behaviors from these four levels of healthcare providers. It follows that the TCI of the referral behavior network can be further decomposed to portray the interdependences of horizontal behaviors and vertical referral behaviors.

This research contributed to existing literature on the relationship between healthcare market competition and quality of care in two aspects: First, this study emphasized the effects of multiple competition indicators (measured by various connectedness indices of the referral behavior network) on the quality of ambulatory care in contrast to previous research on the relationship between a single competition indicator and quality of healthcare. ${ }^{10-16}$ Second, contrary to previous research using patientsharing data without referral information to establish network relationships among healthcare providers, ${ }^{42-44}$ we applied healthcare providers' referral data to directly measure the interdependences of referral behaviors across different levels of healthcare providers. The results generated from this study provide new insights into the relationship between market competition and the quality of ambulatory care.

\section{Materials and Methods Methods}

Ambulatory care services are delivered by four levels of healthcare providers (namely, local clinics, district hospitals, regional hospitals and medical centers) under Taiwan's NHI system. Since there is no compulsory referral policy, each level of healthcare providers has 4 different referral behaviors, we can define a total of 16 referral behaviors (see Figure $1 \mathrm{~A} 1-\mathrm{A} 4$ ) and assign 16 corresponding referral behavior codes, ie, $\left.\mathrm{RBC}_{\mathrm{i}}, i=1,2, \ldots, 16\right)$. These 16 referral behaviors could be further separated into horizontal (Figure 1 B1-B3) and vertical referral behaviors (Figure 1 C1-C3), corresponding to co-opetition behaviors within the same level of healthcare providers under a fixed total budget for healthcare services and collaborative behaviors across different levels of healthcare providers, respectively. Contrary to previous studies that analyzed the social network of healthcare providers using specific network indicators of patient-sharing data (such as degree, density and network ties) to measure either competitive or collaborative behaviors among healthcare providers, ${ }^{45}$ we model the interdependences of referral behaviors from different levels of healthcare providers through the connectedness network of these 16 referral behaviors (as illustrated by Figure 1 D1).

Specifically, we estimated the TCI by measuring the total contribution of spillovers from shocks to 16 referral behaviors to the total forecast error variance through the dynamic connectedness network analysis. Thus, the TCI is an index quantifying the total interdependences of these 16 referral behaviors. Note that we can separate TCI into two 


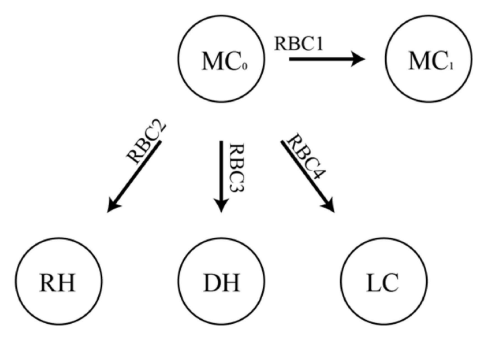

A1 Referral Behaviors from Medical Centers

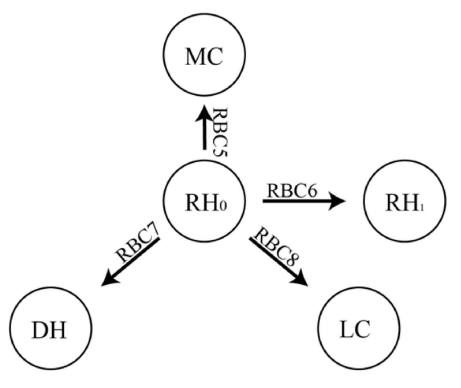

A2 Referral Behaviors from Regional Hospitals

MC
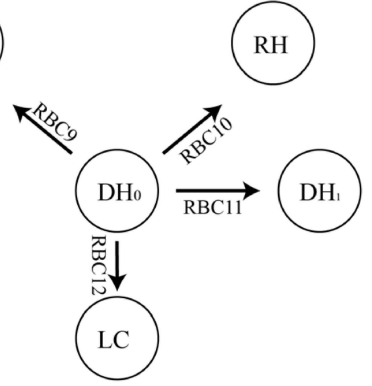

A3 Referral Behaviors from District Hospitals
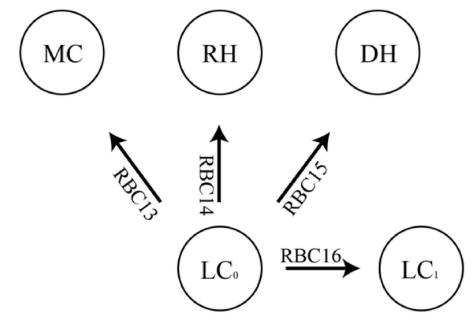

A4 Referral Behaviors from Local

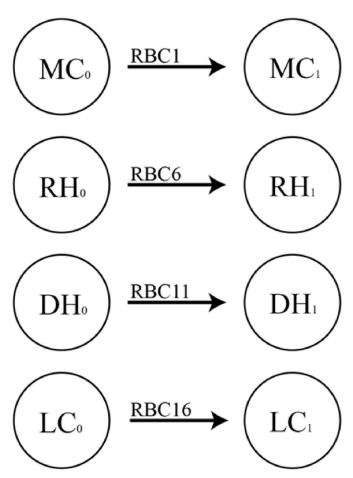

B1 Horizontal Referral Behaviors

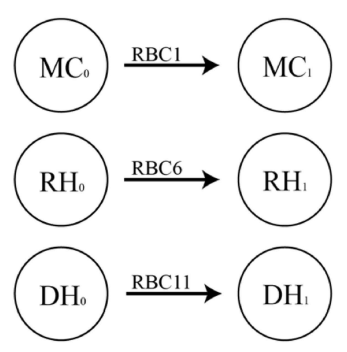

B2 Horizontal Referral Behaviors within Hospital Sector

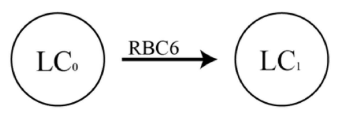

B3 Horizontal Referral Behaviors within Local Clinics

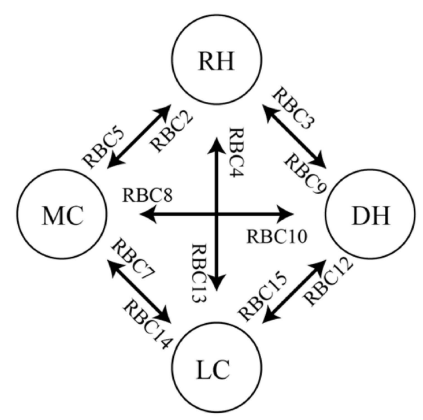

C1 Vertical Referral Behaviors

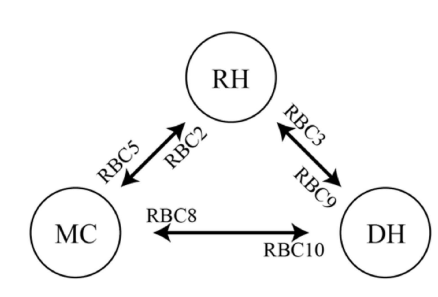

C2 Vertical Referral Behaviors within Hospital Sector

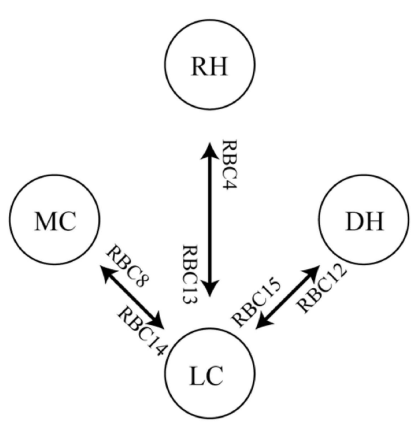

C3 Vertical Referral Behaviors Associated with Local Clinics

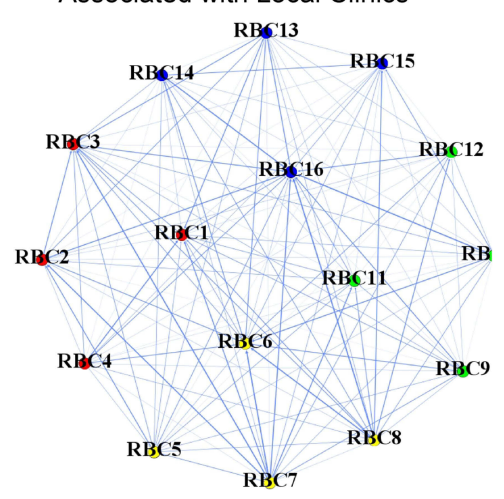

D1 Referral Behavior Network

Figure I Referral behaviors and referral behavior network.

Notes: MC, RH, DH, and LC indicate medical centers, regional hospitals, district hospitals, and local clinics, respectively. $R B C_{i}$ represents referral behavior code $i(i=1,2, \ldots, 16)$ generated from MC, RHw, DH, and LC. The circle icons and arrows in AI-A4, B I-B3, and CI-C3 represent decision-making units, and referral paths, respectively. The red, yellow, green, and blue dots in $\mathbf{D I}$ are referral behavior codes from $M C, R H, D H$, and $L C$, respectively. The blue lines in $\mathbf{D} \mathbf{I}$ represent interdependences of referral behavior network. 
components (HRB and VRB), corresponding to contributions from interdependences of horizontal and vertical referral behaviors, respectively, to total interconnectedness of the referral behavior network, and a further decomposition of the interconnectedness of the referral behavior network contributed by interdependences of horizontal and vertical referral behaviors within the hospital sector (ie, HRBH and VRBH) or associated with local clinics (ie, HRBL and VRBL) can also be computed accordingly (see Section A1 in the online supplementary materials for details). Additionally, the relationship between interdependences of referral behaviors on the quality of ambulatory care could be estimated the Ordinary Least Square (OLS) method with the robust t-statistics in order to avoid a potential serial-correlation bias from the OLS estimation. $^{46}$ The quality of ambulatory care measures used in this study is the prevention quality indicators (PQIs) developed by the US Agency for Healthcare Research and Quality (AHRQ). The PQIs are calculated as hospital admissions per 100,000 population for ambulatory care-sensitive conditions (ACSCs) for which adequate ambulatory care could avoid hospitalization. ${ }^{47}$ These quality indicators should be relevant measures with which to evaluate the quality of ambulatory care under Taiwan's NHI system. Specifically, we regressed the hospital admissions for the ACSCs on explanatory variables (ie, TCI and its decomposition) and control variables (namely, demographic structure and income level). The formal model specification for the OLS is displayed in Section A2 of the online supplementary materials.

\section{Materials}

The data used for the dynamic connectedness network analyses include 16 time series of national ambulatory referral visits to measure 16 referral behaviors generated from local clinics, district hospitals, regional hospitals and medical centers under Taiwan's NHI system. We retrieved weekly time series of aggregate ambulatory referral visits from the National Insurance Research Database in Taiwan over the period from January 1st, 2013 to December 31st, 2018, generating 313 weekly observations. These 16 time series of ambulatory referral visits were proved to be stationary data according to the PP unit root test (see Section A3 in the online supplementary materials for details). Therefore, we applied these data to perform the dynamic connectedness network analyses.

In addition, the 2020 version of the prevention quality indicators (developed by the US AHRQ) included 10 individual PQIs measured by admission rate per 100,000 population. ${ }^{47}$ Three composite measures of PQIs were used to measure the quality of ambulatory care under Taiwan's NHI system. These three composite measures include the PQI_90 (Overall PQI composite measure), PQI_91 (Acute PQI composite), and PQI_92 (Chronic PQI composite measure). All PQIs were computed in accordance with the guidance of the 2020 version of the prevention quality indicators, ${ }^{47}$ and weekly time series of three composite measures were constructed using hospital admission data from the National Insurance Research Database from January 1st, 2013 to December 31st, 2018. Since all three composite measures are aggregate time-series data, the first order of difference of time-series data was taken to assure the stationarity of these three measures of quality of ambulatory care under Taiwan's NHI system.

Furthermore, we retrieved the monthly data of age distribution, labor force, index of average regular earnings of employees in the industrial and services sectors (as a proxy to measure the income level of residents) from the Macroeconomic Statistics and the Demographic Statistics Databases in Taiwan. These data enabled us to calculate the old-age economic dependency ratio (ie, the population aged 65 and above divided by labor force). Since these monthly data belong to the unit root time series, the temporal disaggregation of time-series method proposed by Litterman ${ }^{48}$ was used to obtain the weekly data of these variables in order to prevent potential aggregation of biased relationships between dependent and explanatory variables of weekly frequency data. ${ }^{49}$

\section{Results}

Table 1 displays descriptive statistics and unit root tests of all variables used in equation (A7) (see Section A2 of the online Supplementary materials and Figure 2 for time plots of these variables). In order to prevent false correlation between quality of ambulatory care and the underlying mechanism of market competition, the first-order difference of time series was used to proceed with our analyses. Table 2 presents the relationship between the interconnectedness of the referral behavior network contributed by various types of referral behaviors (such as TCI and its decomposed components of TCI) and the quality of ambulatory care (measured by three composite measures of PQIs). It is important to address that the PQIs measure the worst outcomes of ambulatory care, so the negative (positive) signs of the estimated coefficients represent the beneficial (harmful) effects generated 
Table I Descriptive Statistics of Connectedness Indices and Quality of Care Indicators $\dagger$

\begin{tabular}{|c|c|c|c|c|c|c|c|c|c|}
\hline \multirow[t]{3}{*}{ Variables } & \multirow[t]{3}{*}{ Description } & \multirow{2}{*}{\multicolumn{4}{|c|}{$\frac{\text { Descriptive Statistics }}{\text { Level }}$}} & \multicolumn{4}{|c|}{ Unit Root Tests } \\
\hline & & & & & & \multicolumn{2}{|c|}{ Level } & \multicolumn{2}{|c|}{ Ist Difference } \\
\hline & & Mean & SD & Max & Min & Cons & $\begin{array}{l}\text { Cons \& } \\
\text { Trend }\end{array}$ & Cons & $\begin{array}{l}\text { Cons \& } \\
\text { Trend }\end{array}$ \\
\hline $\mathrm{TCl}$ & $\begin{array}{l}\text { Total Connectedness Index measures total referral } \\
\text { connectedness within the referral behavior } \\
\text { network }\end{array}$ & 88.62 & 0.71 & 91.14 & 83.04 & -10.00 & -10.02 & -23.98 & -24.09 \\
\hline$H R B$ & $\begin{array}{l}\text { Referral connectedness generated from horizontal } \\
\text { referral behaviors from the same level of care } \\
\text { providers }\end{array}$ & 20.14 & 0.47 & 20.89 & 17.34 & -6.55 & -7.52 & -17.37 & -17.28 \\
\hline HRBL & $\begin{array}{l}\text { Referral connectedness generated from horizontal } \\
\text { referral behaviors from local clinics }\end{array}$ & 4.55 & 0.72 & 5.28 & 1.20 & -5.02 & -6.40 & -18.03 & -18.12 \\
\hline $\mathrm{HRBH}$ & $\begin{array}{l}\text { Referral connectedness generated from horizontal } \\
\text { integration behaviors from the hospital sector }\end{array}$ & 15.59 & 0.51 & 17.70 & 14.92 & -1.88 & -2.00 & -16.47 & -16.89 \\
\hline VRB & $\begin{array}{l}\text { Referral connectedness generated from vertical } \\
\text { referral behaviors of care providers from the } \\
\text { different levels of care providers }\end{array}$ & 68.49 & 0.52 & $70.4 I$ & 65.69 & -7.11 & -9.63 & -29.86 & -30.28 \\
\hline VRBL & $\begin{array}{l}\text { Referral connectedness generated from vertical } \\
\text { referral behaviors linking with local clinics }\end{array}$ & 34.63 & 0.70 & 35.78 & 32.66 & -2.68 & -3.59 & -27.93 & -27.88 \\
\hline$V R B H$ & $\begin{array}{l}\text { Referral connectedness generated from vertical } \\
\text { referral behaviors within the hospital sector only }\end{array}$ & 33.86 & 1.02 & 36.46 & 32.62 & -1.75 & -4.26 & -21.19 & -21.21 \\
\hline AGE & Old-age economic dependency ratio (\%) & 25.30 & 1.77 & 28.64 & 22.69 & 2.00 & -1.68 & -3.58 & -3.79 \\
\hline RWI & $\begin{array}{l}\text { Index of Average Regular Earnings of employees } \\
\text { for the industrial and services sectors }\end{array}$ & 99.07 & 2.92 & 105.59 & 94.42 & 1.28 & -2.98 & -3.40 & -3.47 \\
\hline PQ190 & $\begin{array}{l}\text { Prevention Quality Overall Composite, per } \\
100,000 \text { population }\end{array}$ & 69.97 & 5.45 & 86.34 & 20.30 & -8.20 & -8.23 & -26.04 & -26.20 \\
\hline PQI9I & $\begin{array}{l}\text { Prevention Quality Acute Composite, per 100,000 } \\
\text { population }\end{array}$ & 28.29 & 2.49 & 37.30 & 5.35 & -2.50 & -1.97 & -21.93 & -22.11 \\
\hline PQI92 & $\begin{array}{l}\text { Prevention Quality Chronic Composite, per } \\
100,000 \text { population }\end{array}$ & 41.68 & 3.57 & 52.36 & 14.95 & -11.57 & -11.38 & -33.03 & -33.17 \\
\hline
\end{tabular}

Notes: ' $\mathrm{B}$ Bold fonts represent $5 \%$ (or rigorous) significance levels. The computation and definitions for the $T C l, H R B, H R B L, H R B H$, VRB, VRBL, and VRBH can be found in the Section AI of the online supplementary materials.

from the variation of explanatory variables. As indicated in Panel A of Table 2, the TCI has significant and negative effects on three composite measures of hospital admissions for the ACSCs, and the absolute value of the standardized coefficient of TCI for PQI_92 is much higher than that for PQI_91. These results indicate that interdependences of the referral behaviors across hospitals and local clinics benefits the quality of ambulatory care for chronic conditions more substantially than that for acute conditions. Additionally, as shown in Panel B of Table 2, the beneficial effects of interdependences of vertical referral behaviors (VRB) on three composite measures of hospital admissions for the ACSCs have been substantiated, but the interdependence of the horizontal referral behaviors (HRB) does not generate any significant effect on the quality of ambulatory care. In addition, the interdependence of vertical referral behaviors also benefits the quality of ambulatory care for chronic conditions more substantially than that for acute conditions, as indicated by a higher absolute value of the standardized coefficient of VRB for the PQI_92 than that for the PQI_91. 
TCI
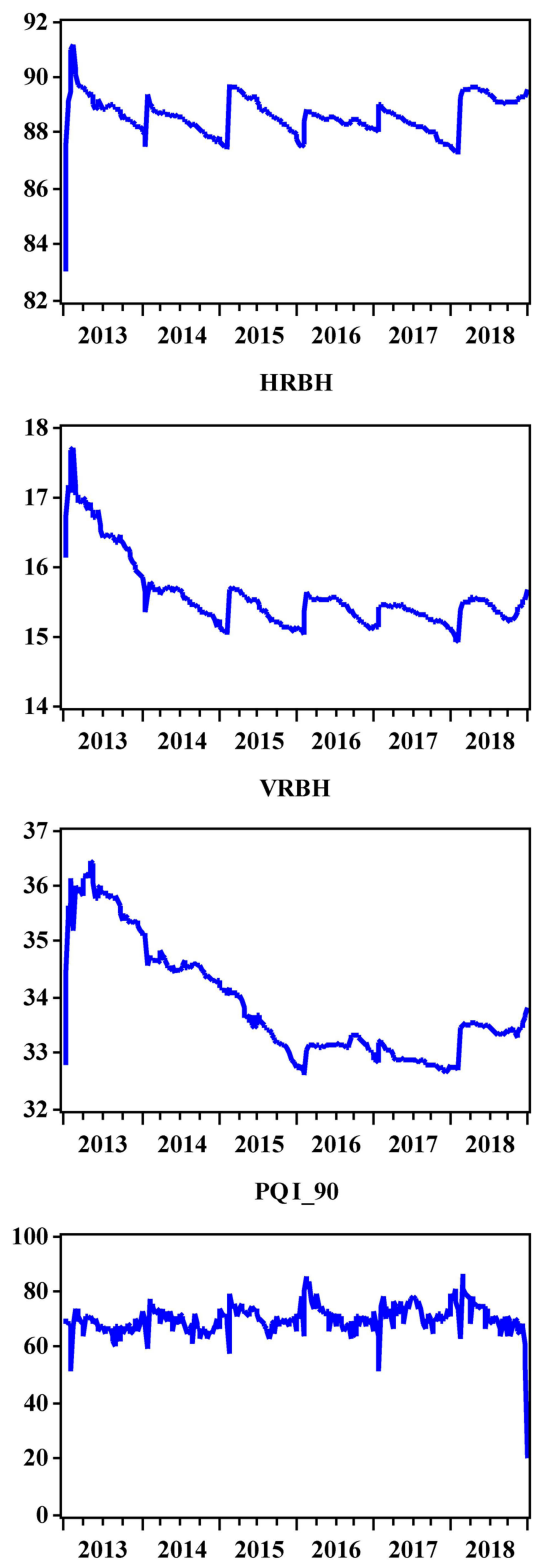

HRB

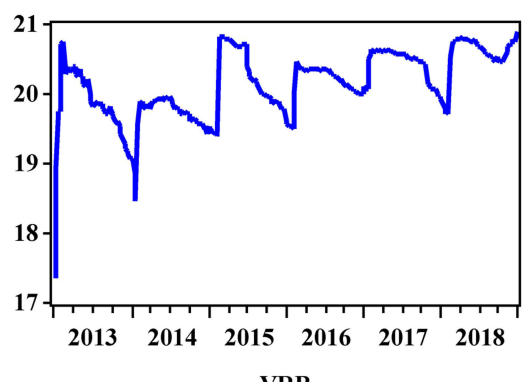

VRB
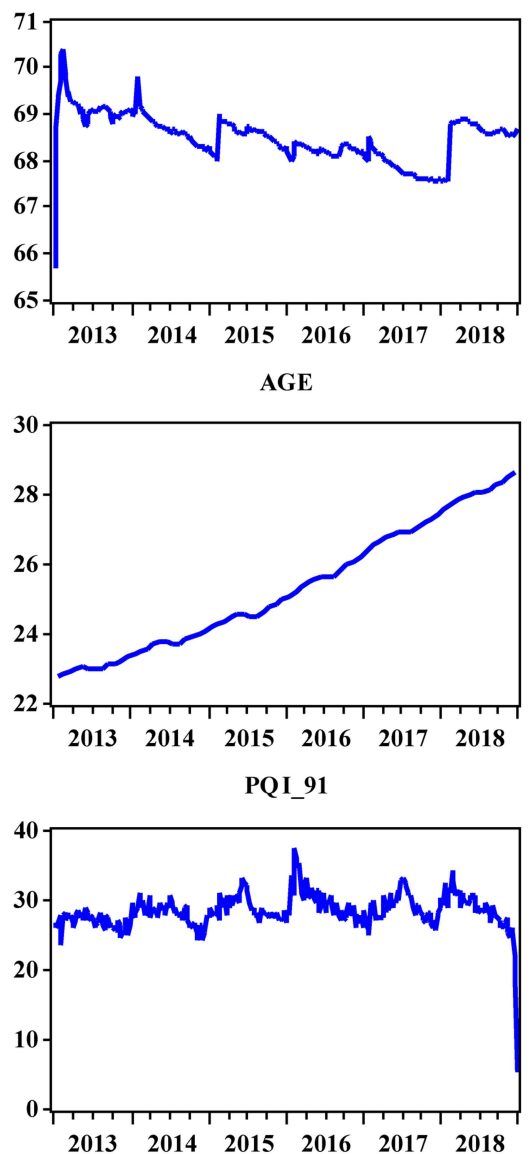

HRBL

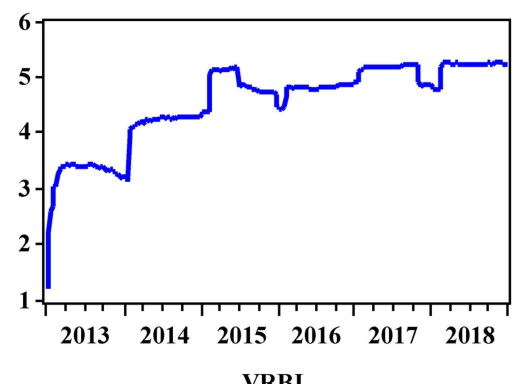

VRBL

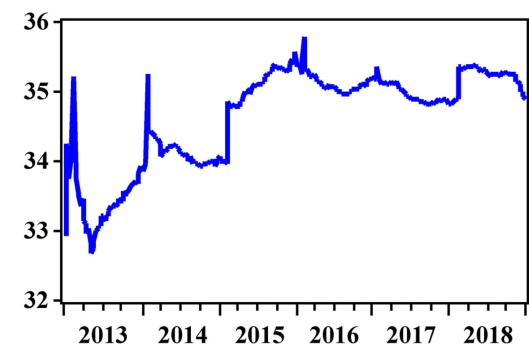

RWI
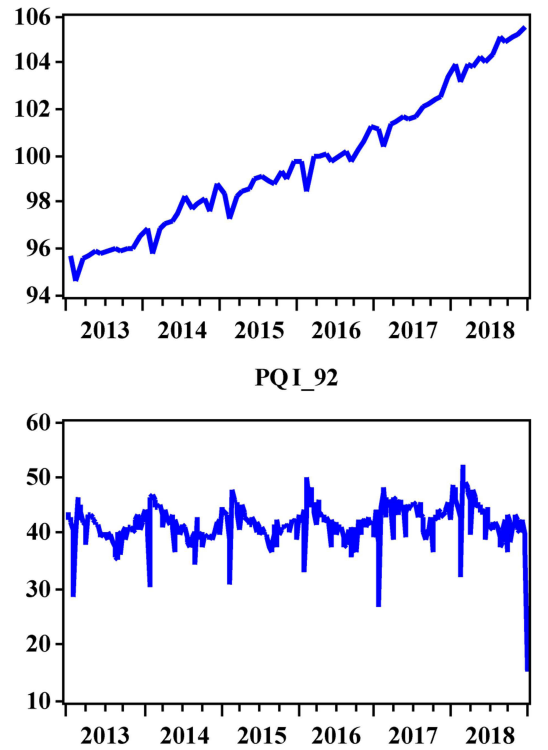

Figure 2 Quality of care indicators vs network connectedness.

Notes: $\operatorname{VRB}(H R B), V R B H(H R B H), V R B L(H R B L)$ represent referral connectedness obtained by the vertical (horizontal) referral behaviors from four different levels of healthcare providers, hospital sector, and local clinics, respectively. $T C l=V R B+H R B=(V R B H+V R B L)+(H R B H+H R B L)$.

Although the interdependence of horizontal referral behaviors within the hospital sector (HRBH) does not show any significant effect, the significantly harmful effects of the interdependence of horizontal referral behaviors within the local clinics sector (HRBL) on three composite measures of hospital admissions for the ACSCs are verified (see Panel C of Table 2). These harmful effects have more influence on the quality of ambulatory care for acute conditions than that for chronic conditions, corresponding to a higher value of the standardized coefficient of HRBL for the PQI_91 than that for the PQI_92. The interdependence of vertical referral behaviors within the hospital sector (VRBH) negatively impacts three composite measures of hospital admissions for the ACSCs, and it benefits the quality of ambulatory care for chronic conditions more substantially than that for acute conditions, as shown by a higher absolute value of the standardized coefficient of VRBH for the PQI_92 than that for the PQI_91. 
The interdependences of vertical referral behaviors associated with local clinics (VRBL) are significantly and negatively associated with the Overall (PQI_90) and Chronic (PQI_92) composite measures of hospital admissions for the ACSCs. It follows that the beneficial effect of the interdependences of vertical referral behaviors associated with local clinics (VRBL) is more significant on the quality of ambulatory care for chronic conditions than that for acute conditions. Moreover, the absolute values of the standardized coefficients of VRBL are higher (lower) than those of VRBH for the PQI_90 and PQI_92 (PQI_91), suggesting that care collaboration between local clinics and hospitals would contribute to a better overall quality of ambulatory care via reduction of the chronic composite measure of hospital admissions for the ACSCs. Finally, we identified a negative and significant relationship between income and Chronic (PQI_92) composite measure of hospital admissions for the ACSCs. The ageing population is most likely to be positively related to three composite measures of hospital admissions for the ACSCs but these relationships are not significant.

\section{Discussion}

Several policy implications obtained from our empirical results have merits that should be addressed: First, the evidence presented in Panel A of Table 2 shows the beneficial effect of the total interconnectedness of the referral behavior network on the quality of ambulatory care across different levels of healthcare providers, and the response of the healthcare providers to market competition leading to a higher connectedness of referral behavior network improves the quality of ambulatory care for chronic conditions more than that for acute conditions. Hence, our findings not only echo the results from the previous studies on the relationship between market competition and quality of healthcare, ${ }^{10-12,16}$ but they are also consistent with the evidence obtained from prior research on the impact of care coordination and patient-sharing networks on the cost and quality of healthcare. ${ }^{33,35-37,39-41}$ Moreover, the share of total healthcare expenditure spent on chronic diseases has increased from $39.9 \%$ to $47.9 \%$ from the period of 2010-2020, and the rapidly increasing rate of population ageing will further expand healthcare spending on chronic diseases in Taiwan. ${ }^{50}$ The results discussed here do provide solid evidence for the importance of promoting and establishing a two-way referral mechanism in order to improve the quality of ambulatory care and constrain healthcare expenditure growth in Taiwan.

Second, it is worth addressing that the horizontal referral behavior is referred to as the co-opetition behavior since referrals of patients within the same level of providers not only indicate the collaboration between two healthcare providers to provide better care for their patients but also imply the healthcare providers' competition for a share of a fixed total budget for healthcare services. The insignificant effects of the interdependences of the horizontal referral behaviors on three composite measures of hospital admissions for the ACSCs shown in Panel B of Table 2 suggest that the beneficial effect of the interdependences of horizontal referral behaviors from care collaboration is probably offset by the harmful effect of the interdependences of horizontal referral behaviors from quantity competition of care within the same level of healthcare providers. Our results resemble the trade-off relationship between collaborative and competitive behaviors in responses to market competition within the same level of healthcare providers identified in the literature addressing the co-opetition relationship in the healthcare market. ${ }^{42-44}$

Third, the previous theoretical research predicts that the global budget payment scheme used to reimburse healthcare services would generate a quality-enhancing and efficiency-improving outcome if managerial slack (consisting of pure inefficiency and consumption in the workplace yielding positive utility of medical staff) is reduced due to market competition. ${ }^{51}$ Our findings shown in Panel $\mathrm{C}$ of Table 2 show that the harmful effect of the interdependences of the horizontal referral behaviors within the local clinics sector is more significant than that of the horizontal referral behaviors within the hospital sector. These results reflect the fact that the reduction of managerial slack in hospitals is most likely to be higher than that in local clinics. In addition, the number of local clinics (hospitals) in Taiwan increased (decreased) from 18,183 (594) in the year 2003 to 22,512 (480) in the year $2019,{ }^{7}$ but the share of the global budget for the local clinics (hospital) sector decreased (increased) from $22.00 \%(65.00 \%)$ to $16.00 \%(67.47 \%)$ during the same period. $^{52,53}$ It follows that the quantity competition of healthcare services in the local clinics sector would be more severe than that in the hospital sector, and that the adverse effect of the interdependences of horizontal referral behavior within the local clinics sector would have a more substantial impact on the quality of ambulatory 
Table 2 Association Between Network Connectedness and Prevention Quality Indicators ${ }^{\dagger}$

\begin{tabular}{|c|c|c|c|c|c|c|}
\hline \multicolumn{7}{|c|}{ Panel A: Total Connectedness of Referral Behavior Network } \\
\hline \multirow[b]{2}{*}{ Variables } & \multicolumn{2}{|c|}{$\triangle P Q 190$} & \multicolumn{2}{|c|}{$\triangle P Q 191$} & \multicolumn{2}{|c|}{$\triangle P Q 192$} \\
\hline & Coef (T-Stat) & $\begin{array}{l}\text { Standardized } \\
\text { Coef }\end{array}$ & Coef (T-Stat) & $\begin{array}{l}\text { Standardized } \\
\text { Coef }\end{array}$ & Coef (T-Stat) & $\begin{array}{l}\text { Standardized } \\
\text { Coef }\end{array}$ \\
\hline$\Delta(T C l)$ & $-2.912(-3.45)^{* * *}$ & -0.218 & $-0.456(-2.42)^{* *}$ & -0.102 & $-2.456(-3.47)^{* * *}$ & -0.241 \\
\hline$\Delta(A G E)$ & $7.606(0.68)$ & 0.022 & $0.079(0.02)$ & 0.001 & $7.527(1.10)$ & 0.029 \\
\hline$\Delta(R W l)$ & $-1.445(-1.10)$ & -0.050 & $-0.910(-2.38)^{* *}$ & -0.094 & $-0.535(-0.45)$ & -0.024 \\
\hline Constant & $-0.200(-1.22)$ & & $-0.032(-0.39)$ & & $-0.168(-1.56)$ & \\
\hline \multicolumn{7}{|c|}{ Panel B: Decomposition by Referral Behaviors } \\
\hline & \multicolumn{2}{|c|}{$\triangle P Q 190$} & \multicolumn{2}{|c|}{$\triangle P Q I 9 I$} & \multicolumn{2}{|c|}{$\triangle P Q 192$} \\
\hline Variables & Coef (T-Stat) & $\begin{array}{l}\text { Standardized } \\
\text { Coef }\end{array}$ & Coef (T-Stat) & $\begin{array}{l}\text { Standardized } \\
\text { Coef }\end{array}$ & Coef (T-Stat) & $\begin{array}{l}\text { Standardized } \\
\text { Coef }\end{array}$ \\
\hline$\Delta(V R B)$ & $-7.448(-2.98)^{* * *}$ & -0.331 & $-1.068(-1.98)^{* *}$ & -0.141 & $-6.379(-2.94)^{* * *}$ & -0.372 \\
\hline$\Delta(H R B)$ & $3.110(0.80)$ & 0.109 & $0.357(0.35)$ & 0.037 & $2.753(0.88)$ & 0.127 \\
\hline$\Delta(A G E)$ & $3.262(0.30)$ & 0.009 & $-0.508(-0.10)$ & -0.004 & $3.769(0.62)$ & 0.014 \\
\hline$\Delta(R W l)$ & $-1.019(-0.97)$ & -0.035 & $-0.852(-2.33)^{* *}$ & -0.088 & $-0.167(-0.17)$ & -0.008 \\
\hline Constant & $-0.155(-1.04)$ & & $-0.026(-0.33)$ & & $-0.129(-1.32)$ & \\
\hline \multicolumn{7}{|c|}{ Panel C: Decomposition by Referral Behaviors of Hospitals and Clinics } \\
\hline & \multicolumn{2}{|c|}{$\triangle P Q 190$} & \multicolumn{2}{|c|}{$\triangle P Q 19 I$} & \multicolumn{2}{|c|}{$\triangle P Q 192$} \\
\hline Variables & Coef (T-Stat) & $\begin{array}{l}\text { Standardized } \\
\text { Coef }\end{array}$ & Coef (T-Stat) & $\begin{array}{c}\text { Standardized } \\
\text { Coef }\end{array}$ & Coef (T-Stat) & $\begin{array}{l}\text { Standardized } \\
\text { Coef }\end{array}$ \\
\hline$\Delta(V R B L)$ & $-8.146(-1.72)^{*}$ & -0.287 & $-0.652(-0.59)$ & -0.069 & $-7.495(-2.05)^{* *}$ & -0.347 \\
\hline$\Delta(V R B H)$ & $-8.291(-3.28)^{* * *}$ & -0.265 & $-2.281(-3.47)^{* * *}$ & -0.218 & $-6.010(-2.98) * * *$ & -0.253 \\
\hline$\Delta(H R B L)$ & $10.691(2.22)^{* *}$ & 0.213 & $3.314(2.47)^{* *}$ & 0.197 & $7.377(1.99)^{* *}$ & 0.193 \\
\hline$\Delta(H R B H)$ & $-3.390(-0.42)$ & -0.065 & $-2.133(-0.90)$ & -0.121 & $\begin{array}{l}-1.258 \\
-0.21\end{array}$ & -0.032 \\
\hline$\Delta(A G E)$ & $4.184(0.42)$ & 0.012 & $0.391(0.08)$ & 0.003 & $\begin{array}{l}3.793 \\
0.57\end{array}$ & 0.014 \\
\hline$\Delta(R W I)$ & $-1.015(-0.99)$ & -0.035 & $-0.819(-2.37)^{* *}$ & -0.085 & $\begin{array}{l}-0.196 \\
-0.20\end{array}$ & -0.009 \\
\hline Constant & $-0.273(-1.45)$ & & $\begin{array}{l}-0.085 \\
-1.12\end{array}$ & & $\begin{array}{l}-0.188 \\
-1.29\end{array}$ & \\
\hline
\end{tabular}

Notes: ${ }^{\dagger}$ T statistics were computed as the estimated coefficients divided by the Newey-West standard errors. “***”, “***”, and “*”” represent I\%, $5 \%$, and I0\% significance levels, respectively. Bold fonts represent $10 \%$ (or rigorous) significance levels.

care for acute conditions than on that for chronic conditions (see Panel $\mathrm{C}$ of Table 2). Hence, the surveillance system established to track the quality of ambulatory care under the global budget payment scheme for the local clinics sector should target ambulatory care services for patients with acute conditions.

Fourth, it is also worth addressing that vertical referral behavior refers to integrated collaboration behavior across 
different levels of healthcare providers. Although the positive effect of the interdependences of vertical referral behaviors on the quality of healthcare has been proved (see the Panel B of Table 2), the findings from Panel C of Table 2 show that the negative effects on the overall and chronic composite measures of hospital admissions for the ACSCs generated from the interdependences of vertical behaviors associated with local clinics would have a more substantial impact than that from the interdependences of vertical behaviors within the hospital sector. The results generated from this study exhibit the significance of care collaboration between local clinics and hospitals in increasing the quality of ambulatory care through decreasing the chronic composite measure of hospital admissions for the ACSCs.

This study is subject to the limitation of data availability. A high frequency of data from weekly ambulatory referral visits and hospital admissions for the ACSCs were collected for the dynamic connectedness network and multiple-linear regression analyses in order to obtain a large sample size that enables us to estimate $120\left(=\mathrm{C}_{2}^{16}\right)$ bidirectional relations between two referral behaviors. Nevertheless, the demographic and income variables that serve as control variables to validate the association between quality of ambulatory care and various connectedness indices of the referral behavior network are reported monthly. Thus, the temporal disaggregation of time-series method was adopted to obtain the weekly data for our control variables. ${ }^{48}$ Finally, despite our results being validated by our empirical models based on the healthcare utilization data from Taiwan, the future research derived from this study is to analyze healthcare utilization data from other countries based on the same analytic framework in order to see whether or not the results obtained from this study are reproducible for other countries.

\section{Conclusions}

The lack of a compulsory referral system under Taiwan's NHI system has long been a source of concern regarding the detrimental effect of this lack on both cost and quality of healthcare services. ${ }^{1,4}$ In this study, we adopted the dynamic connectedness network analysis to investigate the effect of referral behaviors across different levels of healthcare providers on the quality of ambulatory care from a market competition perspective. The results generated from this study not only provide solid evidence regarding the significance of care collaboration across hospitals and local clinics in curbing the avoidable hospital admissions of chronic diseases thus improving the overall quality of ambulatory care, but they also accentuate the importance of ambulatory care quality surveillance for patients with acute conditions in the local clinics sector with reimbursement constrained by the global budget payment scheme under Taiwan NHI system.

\section{Data Sharing and Data Accessibility}

Data used in this study are available upon request to the author.

\section{Ethics Statement}

This research utilized aggregate national data for statistical analyses, and it does not involve human participants or animals. Therefore, informed consent is not applicable for this study. The data collection process was approved by the Research Ethics Committee of Taichung Tzu Chi Hospital with the Certificate of Approval ID:REC109-23.

\section{Acknowledgments}

I would like to thank Dr. Kent Rondeau, the editor-in-chief of the journal and two anonymous referees for their insightful suggestions that allow me to improve the quality of this study. The final proof-reading of the study by Lisa Brutcher (at Washington State University, USA) is deeply acknowledged. All errors are mine.

\section{Funding}

This research has been supported by the Ministry of Science and Technology in Taiwan for the research project entitled "The effect of healthcare providers' referral behaviors on quality of ambulatory care: the dynamic connectedness network analyses under Taiwan's National Health Insurance system" with grant no. 109-2410-H-025-006.

\section{Disclosure}

The author reports grants from Taiwan Ministry of Science and Technology, during the conduct of the study; and no other potential conflicts of interest in this work.

\section{References}

1. Wong L. A guide to Taiwan's health industries. Taipei: PricewaterhouseCoopers(PwC); 2020. Available from: https://www. pwc.tw/en/publications/taiwan-health-industries.html. Accessed August 31, 2021.

2. MOHW. National health insurance statistics 2019. Taipei: National Health Insurance Administration, Ministry of Health and Welfare; 2020. Available from: https://dep.mohw.gov.tw/DOS/lp-4988-113. html. Accessed August 31, 2021.

3. MOHW. National health insurance statistics 1995. Taipei: National Health Insurance Administration, Ministry of Health and Welfare; 1996. Available from: https://dep.mohw.gov.tw/DOS/lp-2957-113. html. Accessed August 31, 2021. 
4. Cheng TM. Taiwan's health care system: the next 20 years. Brookings Op-Ed; 2015. Available from: https://www.brookings. edu/opinions/taiwans-health-care-system-the-next-20-years/. Accessed August 31, 2021.

5. NHIA. Effectiveness of hierarchically integrated healthcare system. Taipei: National Health Insurance Administration, Ministry of Health and Welfare; 2020. Available from: https://dep.mohw.gov.tw/nhic/cp1656-54580-116.html. Accessed August 31, 2021.

6. NHIA. 2020-2021 national health insurance annual report. Taipei: National Health Insurance Administration, Ministry of Health and Welfare; 2021. Available from: https://www.nhi.gov.tw/Nhi_ E-LibraryPubWeb/Periodical/P_Detail.aspx?CPT_TypeID $=8 \& C P$ ID=231. Accessed August 31, 2021.

7. MOHW. 2019 statistics of medical care institution's status \& hospital utilization. Taipei: National Health Insurance Administration, Ministry of Health and Welfare; 2020. Available from: https://dep. mohw.gov.tw/DOS/lp-4931-113.html. Accessed August 31, 2021.

8. Chen WY. The evaluation of co-payment adjustments on emergency department visits under Taiwan's national health insurance system from the economic welfare perspective. Health Policy. 2020;124 (11):1192-1199. doi:10.1016/j.healthpol.2020.03.013

9. Lin YL, Chen WY, Shieh SH. Age structural transitions and copayment policy effectiveness: evidence from Taiwan's national health insurance system. Int $J$ Environ Res Public Health. 2020;17 (12):4183. doi:10.3390/ijerph17124183

10. Jiang Q, Tian F, Liu Z, Pan J. Hospital competition and unplanned readmission: evidence from a systematic review. Risk Manag Healthc Policy. 2021;14:473-489. doi:10.2147/RMHP.S290643

11. Shen VC, Ward WJ, Chen LK. Systematic review and meta-analysis on the effect of hospital competition on quality of care: implications for senior care. Arch Gerontol Geriatr. 2019;83:263-270. doi:10.1016/j.archger.2019.05.001

12. Jung K, Polsky D. Competition and quality in home health care markets. Health Econ. 2014;23(3):298-313. doi:10.1002/hec.2938

13. Pekola P, Linnosmaa I, Mikkola H. Does competition have an effect on price and quality in physiotherapy? Health Econ. 2017;26 (10):1278-1290. doi:10.1002/hec.3402

14. Bowblis J. Market structure, competition from assisted living facilities, and quality in the nursing home industry. Appl Econ Perspect Policy. 2012;34(2):238-257. doi:10.1093/aepp/pps006

15. Brunt CS, Hendrickson JR, Bowblis JR. Primary care competition and quality of care: empirical evidence from Medicare. Health Econ. 2020;29(9):1048-1061. doi:10.1002/hec.4119

16. Gravelle H, Liu D, Propper C, Santos R. Spatial competition and quality: evidence from the English family doctor market. $J$ Health Econ. 2019;68:102249. doi:10.1016/j.jhealeco.2019.102249

17. Antonakakis N, Gabauer D, Gupta R, Plakandaras V. Dynamic connectedness of uncertainty across developed economies: a time-varying approach. Econ Lett. 2018;166:63-75. doi:10.1016/j. econlet.2018.02.011

18. Cooper Z, Gibbons S, Skellern M. Does competition from private surgical centres improve public hospitals' performance? Evidence from the English National Health Service. J Public Econ. 2018;166:63-80. doi:10.1016/j.jpubeco.2018.08.002

19. Burns LR, Goldsmith JC, Sen A. Horizontal and vertical integration of physicians: a tale of two tails. Adv Health Care Manag. 2013;15:39-117.

20. Al-Amin M, Housman M. Ambulatory surgery center and general hospital competition: entry decisions and strategic choices. Health Care Manage Rev. 2012;37(3):223-234. doi:10.1097/ HMR.0b013e318235ed31

21. Courtemanche C, Plotzke M. Does competition from ambulatory surgical centers affect hospital surgical output? J Health Econ. 2010;29(5):765-773. doi:10.1016/j.jhealeco.2010.07.003
22. Karim S, Uddin S, Imam T, Moni MA. A systematic review of network studies based on administrative health data. Int J Environ Res Public Health. 2020;17(7):2568. doi:10.3390/ ijerph17072568

23. DuGoff EH, Fernandes-Taylor S, Weissman GE, Huntley JH, Pollack CE. A scoping review of patient-sharing network studies using administrative data. Transl Behav Med. 2018;8(4):598-625. doi:10.1093/tbm/ibx015

24. An C, O'Malley AJ, Rockmore DN, Stock CD. Analysis of the U.S. patient referral network. Stat Med. 2018;37(5):847-866. doi:10.1002/sim. 7565

25. Ghomrawi H, Funk RJ, Parks ML, Owen-Smith J, Hollingsworth JM. Physician referral patterns and racial disparities in total hip replacement: a network analysis approach. PLoS One. 2018;13(2):e0193014. doi:10.1371/journal.pone.0193014

26. Ray MJ, Lin MY, Weinstein RA, Trick WE. Spread of carbapenem-resistant Enterobacteriaceae among Illinois healthcare facilities: the role of patient sharing. Clin Infect Dis. 2016;63 (7):889-893. doi:10.1093/cid/ciw461

27. Simmering J, Polgreen L, Campbell D, Cavanaugh J, Polgreen P. Hospital transfer network structure as a risk factor for clostridium difficile infection. Infect Control Hosp Epidemiol. 2015;36 (9):1031-1037. doi:10.1017/ice.2015.130

28. Muffly TM, Gonzalez J, Khorshid A, Hajagos J, Kropat G. Medicare patient referral networks to female pelvic medicine and reconstructive surgeons across the United States. Female Pelvic Med Reconstr Surg. 2021;27(2):126-130. doi:10.1097/ SPV.0000000000000751

29. Donohue JM, Guclu H, Gellad WF, et al. Influence of peer networks on physician adoption of new drugs. PLoS One. 2018;13(10): e0204826. doi:10.1371/journal.pone.0204826

30. Hunter RF, de la Haye K, Murray JM, et al. Social network interventions for health behaviours and outcomes: a systematic review and meta-analysis. PLoS Med. 2019;16(9):e1002890. doi:10.1371/ journal.pmed.1002890

31. Geissler KH, Lubin B, Ericson KM. The role of organizational affiliations in physician patient-sharing relationships. Med Care Res Rev. 2020;77(2):165-175. doi:10.1177/1077558718769403

32. Linde S. The formation of physician patient sharing networks in Medicare: exploring the effect of hospital affiliation. Health Econ. 2019;28(12):1435-1448. doi:10.1002/hec.3936

33. Yeh CM, Chou YJ, Lin SK, Liu CJ, Huang N. Patient-sharing relationship between Chinese medicine doctors and other physicians: costs and outcomes of breast cancer survivorship care. J Cancer Surviv. 2021;15(6):922-932. doi:10.1007/s11764-02000985-6

34. Gandré C, Beauguitte L, Lolivier A, Coldefy M. Care coordination for severe mental health disorders: an analysis of healthcare provider patient-sharing networks and their association with quality of care in a French region. BMC Health Serv Res. 2020;20(1):548. doi:10.1186/ s12913-020-05173-x

35. Geva A, Olson KL, Liu C, Mandl KD. Provider connectedness to other providers reduces risk of readmission after hospitalization for heart failure. Med Care Res Rev. 2019;76(1):115-128. doi:10.1177/ 1077558717718626

36. Moen EL, Bynum J. Evaluation of physician network-based measures of care coordination using Medicare patient-reported experience measures. J Gen Intern Med. 2019;34(11):2482-2489. doi:10.1007/ s11606-019-05313-y

37. Ostovari M, Yu D. Impact of care provider network characteristics on patient outcomes: usage of social network analysis and a multi-scale community detection. PLoS One. 2019;14(9):e0222016. doi:10.1371/ journal.pone.0222016 
38. Landon BE, Keating NL, Onnela JP, Zaslavsky AM, Christakis NA, O'Malley AJ. Patient-sharing networks of physicians and health care utilization and spending among Medicare beneficiaries. JAMA Intern Med. 2018;178(1):66-73. doi:10.1001/jamainternmed.2017.5034

39. Carson MB, Scholtens DM, Frailey CN, et al. Characterizing teamwork in cardiovascular care outcomes: a network analytics approach. Circ Cardiovasc Qual Outcomes. 2016;9(6):670-678.

40. Pollack CE, Lemke KW, Roberts E, Weiner JP. Patient sharing and quality of care: measuring outcomes of care coordination using claims data. Med Care. 2015;53(4):317-323. doi:10.1097/ MLR.0000000000000319

41. Lomi A, Mascia D, Vu DQ, Pallotti F, Conaldi G, Iwashyna TJ. Quality of care and interhospital collaboration: a study of patient transfers in Italy. Med Care. 2014;52(5):407-414. doi:10.1097/ MLR.0000000000000107

42. Mascia D, Di Vincenzo F. Understanding hospital performance: the role of network ties and patterns of competition. Health Care Manage Rev. 2011;36(4):327-337. doi:10.1097/HMR.0b013e31821fa519

43. Mascia D, Di Vincenzo F. Dynamics of hospital competition: social network analysis in the Italian National Health Service. Health Care Manage Rev. 2013;38(3):234-247. doi:10.1097/HMR.0b013e3 $1824 \mathrm{ccab} 8$

44. Mascia D, Di Vincenzo F, Cicchetti A. Dynamic analysis of interhospital collaboration and competition: empirical evidence from an Italian regional health system. Health Policy. 2012;105(23):273-281. doi:10.1016/j.healthpol.2012.02.011

45. Gandré C. Social network analysis applied to healthcare data: inventory, discussion and perspectives. HAL Discussion Paper; 2019:hal02054253. Available from: https://hal.archives-ouvertes.fr/hal02054253/document. Accessed August 31, 2021.

46. Chen WY, Liang YW, Lin YH. Is the United States in the middle of a healthcare bubble? Eur J Health Econ. 2016;17(1):99-111. doi:10.1007/s10198-015-0668-y
47. AHRQ. Prevention quality indicators technical specifications updates-version v2020 (ICD 10-CM/PCS). Maryland: Agency for Healthcare Research and Quality; 2020. Available from: https:// www.qualityindicators.ahrq.gov/Modules/PQI_TechSpec_ICD10 v2020.aspx. Accessed August 31, 2021.

48. Litterman RB. A random walk, Markov model for the distribution of time series. J Bus Econ Stat. 1983;1(2):169-173.

49. Alarcon Falconi TM, Estrella B, Sempértegui F, Naumova EN. Effects of data aggregation on time series analysis of seasonal infections. Int $J$ Environ Res Public Health. 2020;17(16):5887. doi:10.3390/ijerph 17165887

50. Lee CY, Tsai P-R. The decrease of prevalence of hyperglycemia, hyperlipidemia, and hypertension by $1 \%$ will reduce over NT $\$ 10$ billion of national health expenditure. udn.com; 2021. Available from: https://udn.com/news/story/7266/5353210. Accessed August 31, 2021.

51. Chen WY, Lin YH. Hospital non-price competition under global budget payment and prospective payment system. Expert Rev Pharmacoecon Outcomes Res. 2008;8(3):301-308. doi:10.1586/ 14737167.8.3.301

52. MOHW. 2019 trends of national health insurance statistics. Taipei: National Health Insurance Administration, Ministry of Health and Welfare; 2021. Available from: https://dep.mohw.gov.tw/DOS/lp5126-113.html. Accessed August 31, 2021.

53. MOHW. 2003 trends of national health insurance statistics. Taipei: National Health Insurance Administration, Ministry of Health and Welfare; 2005. Available from: https://dep.mohw.gov.tw/DOS/lp2460-113.html. Accessed August 31, 2021.
Risk Management and Healthcare Policy

\section{Publish your work in this journal}

Risk Management and Healthcare Policy is an international, peerreviewed, open access journal focusing on all aspects of public health, policy, and preventative measures to promote good health and improve morbidity and mortality in the population. The journal welcomes submitted papers covering original research, basic science, clinical \& epidemiological studies, reviews and evaluations, guidelines, expert opinion and commentary, case reports and extended reports. The manuscript management system is completely online and includes a very quick and fair peer-review system, which is all easy to use. Visit http://www.dovepress.com/testimonials.php to read real quotes from published authors. 